\title{
DESENVOLVIMENTO E SAÚdE: A DECLARAÇÃO DE ALMA-ATA E MOVIMENTOS POSTERIORES
}

Em setembro de 1978 foi realizada a primeira Conferência Internacional sobre Cuidados Primários de Saúde, organizada pela OMS e UNICEF em Alma-Ata, capital do Kazaquistão. A Conferência foi assistida por mais de 700 participantes e resultou na adoção de uma Declaração que reafirmou o significado da saúde como um direito humano fundamental e uma das mais importantes metas sociais mundiais.

De acordo com a Declaração de Alma-Ata ${ }^{(1)}$, ações dos diferentes atores internacionais no sentido de diminuir as diferenças no desenvolvimento econômico e social dos países deveriam ser estimuladas para que se atingisse a meta de saúde para todos no ano 2000, reduzindo-se a lacuna existente entre o estado de saúde dos países em desenvolvimento e desenvolvidos. Naquela ocasião, chegou-se ao consenso de que a promoção e proteção da saúde dos povos é essencial para o contínuo desenvolvimento econômico e social e, conseqüentemente, condição única para a melhoria da qualidade de vida dos homens e para a paz mundial. $\mathrm{O}$ apelo lançado em Alma-Ata foi um marco fundamental e representou o ponto de partida para outras iniciativas.

Assim, em 1986, a Carta de Ottawa ${ }^{(2)}$, elaborada na Conferência do Canadá, listou condições e recursos fundamentais, identificando campos de ação na promoção da saúde e ressaltando a importância da eqüidade. Seguindo este direcionamento, em 1988, a Conferência da Austrália ${ }^{(3)}$ enfatizou a importância das políticas públicas como pressuposto para vidas saudáveis, destacando a responsabilidade das decisões políticas, especialmente as de caráter econômico para a saúde.

Na Suécia, foi organizada a terceira Conferência Internacional sobre Promoção da Saúde ${ }^{(4)}$ em 1991, precedendo a Conferência Mundial sobre o Meio Ambiente realizada no Rio de Janeiro em 1992. Durante este evento destacou-se a ecologia e a saúde, concluindo-se que são interdependentes e inseparáveis. Como conseqüência, as políticas governamentais deveriam estabelecer prioridades de desenvolvimento que respeitassem esta inter-relação.

A quarta Conferência foi realizada em Bogotá( ${ }^{(5)}$, Colômbia, em 1992 trazendo a discussão para a situação da saúde na América Latina, na busca de transformar as relações existentes e conciliar interesses econômicos e propósitos sociais de bem estar. $O$ documento elaborado reiterou a necessidade de mais opções nas ações de saúde pública, orientadas para combater o sofrimento causado pelas enfermidades oriundas do atraso e da pobreza, bem como as derivadas da urbanização e da industrialização nos países em desenvolvimento.

Em 1998, a Assembléia Mundial da Saúde adotou uma Declaração reiterando a estratégia de Saúde para Todos no Século XXI e a necessidade de implementação de novas políticas nacionais e internacionais.

Nesta perspectiva, em 2004, observa-se que a humanidade, representada por diferentes atores sociais, ainda busca transformar o paradigma vigente para a saúde, conciliando paradoxos e desigualdades crescentes entre fatores de natureza social, econômica, política, cultural e ambiental.

Em todos os documentos citados previamente menciona-se o desafio de reorientação dos serviços de saúde. A materialização desta meta só será possível com a crescente conscientização dos tomadores de decisão, bem como dos responsáveis pelo cuidado à saúde em instâncias acadêmicas, prestadoras de serviços, políticas, associativas, filantrópicas e do terceiro setor, de modo a envolver segmentos distintos da sociedade. Neste contexto, nós, enfermeiros,

\footnotetext{
${ }^{1}$ Editor da Revista Latino-Americana de Enfermagem, Diretor, Professor Titular da Escola de Enfermagem de Ribeirão Preto, da Universidade de São Paulo, Centro Colaborador da OMS para o desenvolvimento da pesquisa em enfermagem, e-mail: iamendes@eerp.usp.br
} 
desempenhamos um papel fundamental, como cuidadores, educadores e promotores da saúde. Enfim, somos peça chave na geração de uma nova cultura da saúde, caracterizada pela humanização e integralização do cuidado ao ser humano, único caminho para o tão sonhado "desenvolvimento" preconizado pela Declaração de Alma-Ata há um quarto de século.

DESCRITORES: saúde, política de saúde, enfermagem, recursos humanos, cuidado, humanização em saúde

\section{REFERÊNCIAS BIBLIOGRÁFICAS}

1. Declaração de Alma-Ata. Conferência Internacional sobre cuidados primários de saúde; 6-12 de setembro 1978; Alma-Ata; USSR. In: Ministério da Saúde (BR). Secretaria de Políticas de Saúde. Projeto Promoção da Saúde. Declaração de Alma-Ata; Carta de Ottawa; Declaração de Adelaide; Declaração de Sundsvall; Declaração de Santafé de Bogotá; Declaração de Jacarta; Rede de Megapaíses; Declaração do México. Brasília (DF): Ministério da Saúde; 2001. p. 15.

2. Carta de Ottawa. Primeira Conferência Internacional sobre promoção da saúde; novembro de 1986; Ottawa; Ca. In: Ministério da Saúde (BR). Secretaria de Políticas de Saúde. Projeto Promoção da Saúde. Declaração de Alma-Ata; Carta de Ottawa; Declaração de Adelaide; Declaração de Sundsvall; Declaração de Santafé de Bogotá; Declaração de Jacarta; Rede de Megapaíses; Declaração do México. Brasília (DF): Ministério da Saúde; 2001. p. 19.

3. Declaração de Adelaide. Segunda Conferência Internacional sobre promoção da saúde; 5-9 de abril 1988; Adelaide; Au. In: Ministério da Saúde (BR). Secretaria de Políticas de Saúde. Projeto Promoção da Saúde. Declaração de Alma-Ata; Carta de Ottawa; Declaração de Adelaide; Declaração de Sundsvall; Declaração de Santafé de Bogotá; Declaração de Jacarta; Rede de Megapaíses; Declaração do México. Brasília (DF): Ministério da Saúde; 2001. p. 25.

4. Declaração de Sundsvall. Terceira Conferência Internacional de promoção da saúde; 9-15 de junho 1991; Sundsvall; Su. In: Ministério da Saúde (BR). Secretaria de Políticas de Saúde. Projeto Promoção da Saúde. Declaração de Alma-Ata; Carta de Ottawa; Declaração de Adelaide; Declaração de Sundsvall; Declaração de Santafé de Bogotá; Declaração de Jacarta; Rede de Megapaíses; Declaração do México. Brasília (DF): Ministério da Saúde; 2001. p. 33.

5. Declaração de Santafé de Bogotá. Conferência Internacional de promoção da saúde; 9-12 de novembro $1992 ;$ Santafé de Bogotá; Co. In: Ministério da Saúde (BR). Secretaria de Políticas de Saúde. Projeto Promoção da Saúde. Declaração de AlmaAta; Carta de Ottawa; Declaração de Adelaide; Declaração de Sundsvall; Declaração de Santafé de Bogotá; Declaração de Jacarta; Rede de Megapaíses; Declaração do México. Brasília (DF): Ministério da Saúde; 2001. p. 15. 